\title{
Neurorights: the Chilean constitutional change
}

\author{
Allan McCay ${ }^{1}$ \\ Received: 2 January 2022 / Accepted: 31 January 2022 \\ (c) The Author(s), under exclusive licence to Springer-Verlag London Ltd., part of Springer Nature 2022
}

Towards the end of 2021, Chile became the first nation in the world to have a constitution in force that explicitly addresses the challenges of emerging neurotechnologies. Whilst this legislative response to technologies that draw on knowledge pertaining to neuroscience and artificial intelligence received some international media attention, it deserved more. The modification of the constitution might even be thought of as an important historic event given that emerging neurotechnologies have the potential to gather data from our brains, or even to manipulate them, thereby influencing what we think or do. Chile is the first country in the world to directly address the human rights challenges.

The Chilean constitution as it now stands requires that technological development respect people's physical and mental integrity and it states that the law must especially protect brain activity and information related to it.

This development is a response to growing calls to respect "neurorights". Proponents of neurorights worry that neurotechnologies, such as those being developed by Elon Musk's company Neuralink, have the capacity to interfere with our thought processes and behaviour, perhaps thereby infringing what they argue is our right to mental integrity, and revealing information about mental states in a way that is concerning, and thus an infringement of our right to mental privacy.

They further worry that such neurorights are not adequately protected by existing human rights law and call for law reform. Columbia University professor of neuroscience, Rafael Yuste envisages important benefits flowing from neurotechnology, but has also been a significant figure in such calling for the recognition of neurorights. He and other advocates are organising, as is demonstrated by formation of the New York-based NeuroRights Foundation.

With regard to addressing the worries of such advocates, Chile is a world leader. But is this legal action premature?

\footnotetext{
Allan McCay

allan.mccay@sydney.edu.au

1 Sydney Law School, The University of Sydney, Law School Building (F10) Eastern Avenue, Camperdown Campus, Sydney, NSW 2006, Australia
}

Has Chile legislated to protect rights that are under threat only in science fiction?

Neurotechnologies that influence people's thought process have been a staple of science fiction for quite some time. Whether we think of the 1970s film Terminal Man, the Japanese manga series The Ghost in the Shell, or more recently numerous episodes of the Netflix series Black Mirror, science fiction has long been preoccupied with technological mindreading, manipulation of behaviour and the potential of humans to control devices directly with their minds.

But now technology exists that enables people with disabilities to control cursors or other devices by thought or even to control a drone. Technology also exists which enables the presentation of images seen by a person to be displayed on a computer screen. This can happen by way of a device that reads people's brain activity and converts this data into images representing what is seen or even imagined.

There is a significant interest in all of this from a variety of organisations. Agencies such the Defence Advanced Research Projects Agency (a body which aims to preserve the USA's technological advantage in the military context) has quite a history of devoting resources to neurotechnology and has various current projects. Medical companies such as Synchron are also working on various therapeutic applications. Elon Musk's company Neuralink has both medical and non-medical uses of neurotechnology in their sights. In fact, Mr Musk envisages that one day one will be able to summons one's Tesla vehicle by way of mental action rather than going to the trouble of walking towards it.

Perhaps, the thing that has really changed is that while neurotechnology has been around for some time, until fairly recently it has largely been pursued by universities or military agencies such as DARPA. But now there is a race on to commercialise neurotechnology and use it in all sorts of contexts including the workplace and for computer gaming. Companies such as Facebook's CTRL Labs, Emotiv, Kernel and a host of others join Neuralink and Synchron are in a race to make money from this technology.

But is all this activity a good or bad thing? Like so many technological advances, it is something of a double-edged 
sword. Air travel brought us the opportunity to visit far flung places, but also to spread disease and destroy the environment, and neurotechnology is likely to be a mixed blessing and to come with worrying downsides.

Given that advances in neurotechnology may allow people with forms of paralysis to gain control over devices and decrease their reliance on others, the technology is nothing short of wonderful. To aim to give autonomy to people who lack it is a worthy goal by any standard and must be pursued. If neurotechnology also has the potential to cure epilepsy, depression and dementia, then it is hard to dismiss it as something that is not worthwhile.

But what about the dark side of this technology? Here, we might consider hypothetical examples from an area that I am interested in, criminal justice. There is a range of criminal justice systems around the world, some more respectful of human rights than others. What if some systems started to decrease their reliance on techniques that have been used in the past to gain information from suspects, such as interviewing them in favour of more direct brain reading? Perhaps, by showing someone a crime scene image whilst the suspect was wearing a brain-reading device, it would be possible to see if the device picked up any neural activity associated with the suspect having seen that scene before.

What if upon conviction an impulsive and aggressive offender was fitted with a brain implant that, by way of algorithmic means, monitored their brain for neural activity associated with an angry outburst and electrically stimulated the brain to pacify them if they got angry? Maybe this is not such a great step, as some criminal justice systems already electronically monitor offenders' geographical position.

A global group of researchers including myself and Rafael Yuste have considered the possibility of brain-monitoring devices that from time to time intervene on the brain of mentally ill people to prevent them from committing crimes. Should the courts order brain monitoring of this kind? Is it ethically acceptable that an algorithm 'decides' when electrical stimulation is needed to stop a mentally ill person from committing a crime?

Moving away from criminal justice, perhaps employers might wish to monitor the brains of their employees to see if they are attentive enough to their work. Perhap,s one's workplace brain device might be hacked and someone else might engage in brain monitoring or even manipulation.

There is a lot to think about here and, given the commercial activity that is under way, perhaps the question is not whether the Chileans have acted too soon, but whether other countries are considering questions relating to neurorights with enough urgency.

Senator Girardi, a key figure in the recent Chilean reform, is right to point out that there is another technology that, with the benefit of hindsight, we were a bit slow to respond to and that is social media. There now seem to be some tricky social issues that have emerged from that technology, and it is not entirely clear what to do about them. Neurotechnological developments might have more profound implications for society and perhaps we should not wait to act until the changes are entrenched.

It has always been possible to guess what is in others' minds and to use that to influence them, but one can only speculate on what life might be like as corporations, governments and perhaps other individuals gain increasingly precise and reliable information about our mental states, and increasing capacity to manipulate what we think and how we behave. The debate about this is already fairly mainstream in respect to AI, but the related field of neurotechnology is still at the margins of the public forum, and in most countries absent from the political agenda.

Of course, we do not really know what the impact of neurotechnology will be or how the Chilean constitutional change will affect it. We do not know if the Chilean approach is the right one; but one thing is clear, the Chileans have recognised that brain reading and brain manipulation are no longer the exclusive province of science fiction. Other countries should do the same.

Curmudgeon Corner Curmudgeon Corner is a short opinionated column on trends in technology, arts, science and society, commenting on issues of concern to the research community and wider society. Whilst the drive for super-human intelligence promotes potential benefits to wider society, it also raises deep concerns of existential risk, thereby highlighting the need for an ongoing conversation between technology and society. At the core of Curmudgeon concern is the question: What is it to be human in the age of the AI machine? -Editor.

Publisher's Note Springer Nature remains neutral with regard to jurisdictional claims in published maps and institutional affiliations. 